\title{
Paciente con dolor lumbar y enfisema subcutáneo en miembro inferior derecho
}

\author{
Fuentes Esteban D. ${ }^{1}$, Bartolomé Cela E. ${ }^{2}$, Molina López-Nava P. ${ }^{3}$, Carretero Quevedo A. ${ }^{4}$
}

Sanid. mil. 2013; 69 (1): 61-62; ISSN: 1887-8571

Varón de 65 años sin alergias conocidas que ingresa en el servicio de UVI por presentar malestar general, dolor incoercible en miembro inferior derecho y síndrome de respuesta inflamatoria sistémica grave con $35,8^{\circ} \mathrm{C}$ de temperatura, leucocitosis, taquicardia y acidosis láctica.

Procedente del servicio de Neurocirugía donde el paciente ingresó por presentar unas horas antes dolor incapacitante en región lumbar con hipostesias en silla de montar, (cintura pélvica, pubis y tercio superior de muslos), dificultad para la bipedestación e incontinencia miccional. En la exploración destaca la crepitación en el tercio superior del muslo de la pierna derecha a la palpación.

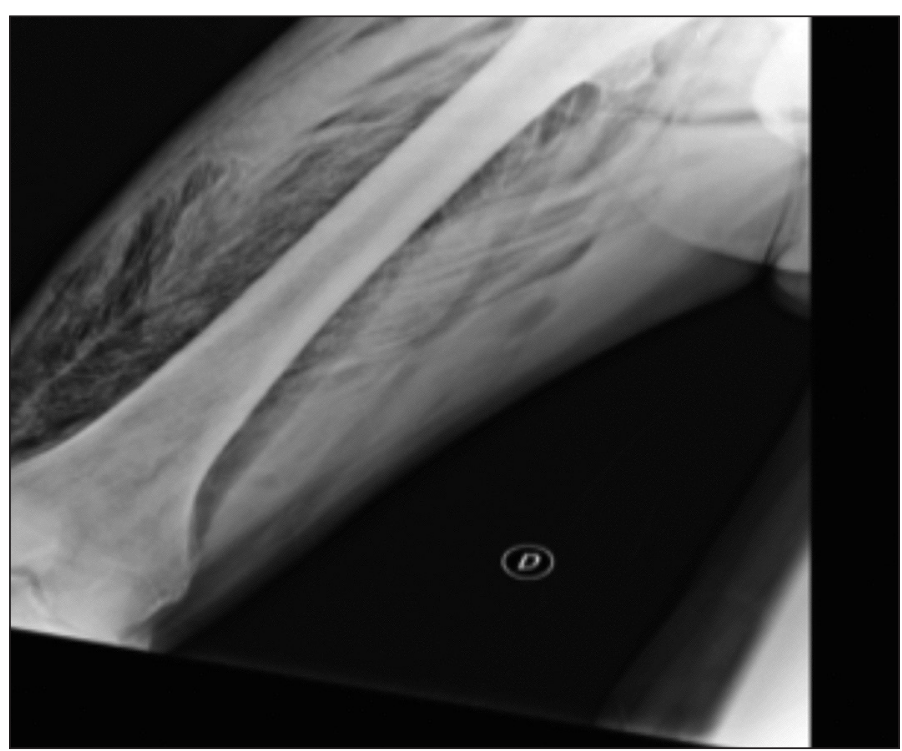

Figura 1.
Se solicitan estudios de imagen en la que destacan la placa simple del miembro inferior derecho y la TC abdominopélvico y de miembros inferiores.

En la radiografía simple del miembro inferior derecho (Figura 1) se ven imágenes hipodensas de partes blandas; algunas de disposición lineal que parecen disecar planos musculares.

También se realiza TC abdominopélvico con contraste oral e intravenoso, (Figura 2) donde se observan extensas colecciones de gas disecando los planos musculares y rodeando los vasos sanguíneos, vena femoral común y safena interna.

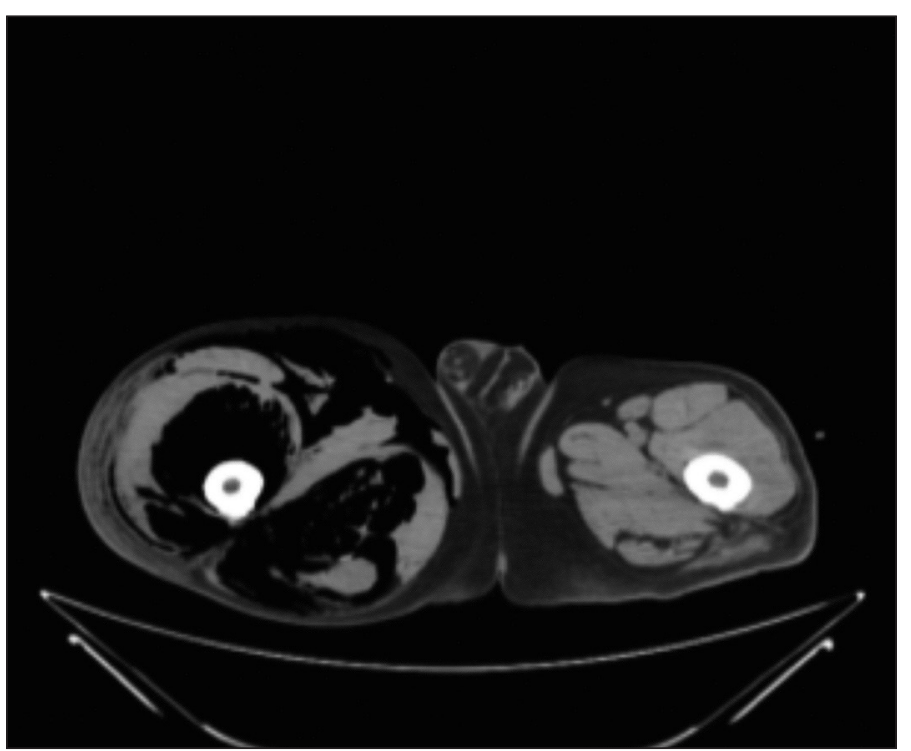

Figura 2.

${ }^{1}$ Cap. Médico. Servicio de Medicina Intensiva.

2 Tcol. Médico. Servicio de Medicina Intensiva.

3 Tcol. Médico. Servicio de Radiodiagnóstico.

${ }^{4}$ Col. Médico. Servicio de Medicina Intensiva.

Dirección para correspondencia: aquiles20071@hotmail.es

Recibido: 1 de febrero de 2011

Aceptado: 20 de noviembre de 2012 


\section{Diagnóstico: Fascitis necrotizante por Clostridium perfiringens}

En la UVI se tomaron muestras microbiológicas para cultivos, donde crecieron Clostridium perfringens en sangre y tejido muscular de la pierna derecha. Finalmente y a pesar de las medidas de estabilización adecuadas y de trasladar al paciente a quirófano para evitar un síndrome compartimental, el paciente fallece en el trascurso de 24 horas desde su llegada al hospital.

Se realizó necropsia en la que se encontraron Clostridium perfringens diseminados por toda la anatomía, cerebelo, pulmones, intestino, testículo, además del citado miembro inferior derecho. El informe sugiere una posible contaminación exógena por inyecciones en domicilio de AINEs $^{1}$ o bien una traslocación intestinal debido a una diverticulitis intestinal asintomática que se valoró en el estudio del cadáver.

El Clostridium perfringens es una bacteria Gram positiva anaerobia con capacidad para formar esporas. Está ampliamente distribuido en la naturaleza, principalmente en el suelo y en el tracto intestinal de muchas especies animales incluido el hombre. Hay 5 tipos de Clostridium perfringens y producen toxinas que pueden causar diferentes alteraciones, casi todas tienen un poder necrótico y letal, así como provocar hemólisis, destacando la alfa que destruye las membranas celulares produciendo la necrosis muscular, la toxina theta que produce lisis leucocitaria, la endotoxina $\mathrm{M}$ que es la responsable de las burbujas de gas y la beta que aunque no está en todas las cepas de Clostridium es la que causa enteritis necrotizante ${ }^{2}$.

Va a causar diferentes tipos de infecciones que se pueden manifestar como: a) celulitis crepitante, infección que afecta a los tejidos subcutáneos o retroperitoneales, el músculo no suele estar afecto en una extensión significativa y permanece viable. Los hallazgos en el lugar de la infección incluyen crepitación a la palpación por la presencia de gas, dolor, edema, ligera decoloración de la piel y exudado oscuro, frecuentemente maloliente; b) gangrena gaseosa, esta infección surge principalmente después de un traumatismo, como complicación de una herida penetrante y extensa, usualmente en una extremidad y con gran afectación de la masa muscular, o bien como complicación de una cirugía. Se presenta con un curso rápidamente progresivo y devastador, caracterizado por una necrosis muscular y una grave toxicidad sistémica, con taquicardia, fiebre de bajo grado y una extrema ansiedad. Se suele observar gas por palpación, radiografía o escáner, aunque la crepitación puede ser un signo tardío.

Un signo específico de la fascitis necrotizante y sus manifestaciones, que se valora con las técnicas de imagen como la TC, es la formación de gas en tejidos subcutáneos y acumulación de líquido dentro de la fascia profunda, aunque no está presente en todos los casos. Otros hallazgos son: engrosamiento del tejido adiposo subcutáneo y al menos de una de las capas fasciales, (superficial o profunda), ausencia de realce de dichas fascias, linfadenopatía reactiva y finalmente, edema en músculos y en septos intermusculares ${ }^{3,4}$.

El tratamiento de la bacteriemia por Clostridium perfringens se basa en realizar unas medidas generales para resolver el cuadro infeccioso tales como una correcta monitorización hemodinámica con infusión de fluidos, un buen soporte ventilatorio y finalmente la administración de hidrocortisona en caso de insuficiencia suprarrenal. Y unas medidas específicas que se basan en antibioterapia empírica inicial con Penicilinas y Clindamicina, que ya se especificará cuando lleguen los resultados del antibiograma tras la realización de cultivos ${ }^{5,6}$.

La infección por Clostrudium perfringens es una infección potencialmente mortal, de rápida evolución sobre procesos patológicos muy variados, que no nos hace pensar de inicio en ella, por lo que se debe realizar un rápido y correcto diagnóstico y tratamiento debido a la rápida mortalidad que dicha infección conlleva ${ }^{7}$.

\section{BIBLIOGRAFÍA}

1. Brown P.D, Ebright J.R. Skin and soft tissue infections in injection drug users. Current Infect Dis Rep 2002; 4:415-419.

2. Kasper D.L., Zalaznik D.F. Gangrena gaseosa y otras infecciones por Clostridios. En: Fauci A.S., Braunwald E., Isselbacher K.J., Wilson J.D., Marti J.B., Kasper D.L., et al. Principios de Medicina Interna.14a ed. Madrid: McGraw-Hill Interamericana de España 1997:1034-40.

3. Fugitt, J.B., Puckett M.L., Quingley M.M., Kerr S.M. Necrotizing fasciitis. RadioGraphics, 2004; 24: 1472-1476.

4. Perez Bea M, Grau García M, Ibañez Zubiarrain A, Barcena Robredo M V, Isusi Fontan A, Grande Icaran D. Utilidad de la TC en la fascitis necrotizante. Radiología Abdominal 2011; 9:27-28.

5. Allen S.D., Emery C.L., Lyerly D.M. Clostridium. En: Murray P.R., Baron E.J., Jorgensen J.H., Pfaller M.A., Yolken R.H. Manual of Clinical Microbiology, $8^{\mathrm{a}}$ ed. Washington DC. ASM Press 2003:835- 856.

6. Pérez Trallero E., Cueto M., Miranda C. Bacilos grampositivos. En: de la Rosa M, Prieto J. Microbiología en ciencias de la salud. Conceptos y aplicaciones, $2^{\mathrm{a}}$ ed. Madrid: Elsevier, 2003:84-90.

7. Martos F., Reguer J.M., Seara R., Dominguez,F., Contreras J, Garcia-Delange, T. Septicemia por Clostridium perfringens en ausencia de factores predisponentes. Enferm Infecc Microbiol Clin 1995;13:187-8. 